\title{
Qualidade de sementes de milho em resposta à adubação nitrogenada e à inoculação com bactérias diazotróficas
}

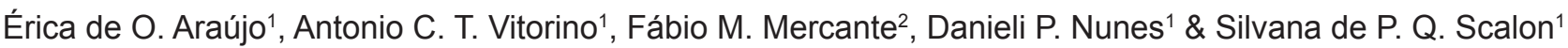

\begin{abstract}
1 Universidade Federal da Grande Dourados, Faculdade de Ciências Agrárias, Rodovia Dourados/tahum, km 12, Cidade Universitária, CEP 79804-970, Dourados-MS, Brasil. Caixa Postal 533.E-mail: ericabb25@hotmail.com; vitorino@ufgd.edu.br; danipiereti@gmail.com; silvanapqs@ufgd.edu.br

${ }^{2}$ Empresa Brasileira de Pesquisa Agropecuária, Centro de Pesquisa Agropecuária do Oeste, BR 163, Km 253, Zona Rural, CEP 79804-970, Dourados-MS, Brasil. Caixa Postal 449. E-mail: fabiomercante@hotmail.com
\end{abstract}

\section{RESUMO}

Na busca de elevação dos níveis atuais de produtividade e redução nos custos de produção de sementes de milho no Brasil, novas tecnologias vêm sendo incorporadas ao sistema de produção, razão por que se objetivou, no presente trabalho, avaliar a qualidade fisiológica de sementes de milho em resposta à adubação nitrogenada e à inoculação com Azospirillum brasilense e Herbaspirillum seropedicae. Para isso foram instalados dois experimentos, o primeiro em delineamento experimental de blocos casualizados e o segundo inteiramente casualizado, ambos com nove tratamentos (controle sem $\mathrm{N}$ e sem inoculação, controle

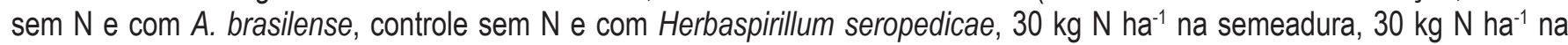
semeadura $+A$. brasilense, $30 \mathrm{~kg} \mathrm{~N}^{-1}$ na semeadura $+H$. seropedicae, $30 \mathrm{~kg} \mathrm{~N} \mathrm{ha}^{-1}$ na semeadura $+90 \mathrm{~kg} \mathrm{~N}^{-1} \mathrm{ka}^{-1}$ cobertura, $30 \mathrm{~kg} \mathrm{~N}^{-1}$ na semeadura $+A$. brasilense $+90 \mathrm{~kg} \mathrm{~N}^{-1}$ na cobertura e $30 \mathrm{~kg} \mathrm{~N} \mathrm{ha}^{-1}$ na semeadura $+H$. seropedicae +90 $\mathrm{kg} \mathrm{N} \mathrm{ha}^{-1}$ na cobertura) e quatro repetições. As variáveis avaliadas foram: porcentagem e primeira contagem de germinação, comprimento e massa seca de plântulas, envelhecimento acelerado, teste de frio e condutividade elétrica. 0 comprimento de plântulas e a produção de massa seca são afetados pela inoculação com as bactérias diazotróficas em associação com adubação nitrogenada. A inoculação das sementes de milho com A.brasilense, $H$. seropedicae e o uso da adubação nitrogenada promovem aumentos na produtividade de sementes de milho, da ordem de 4,73; 5,17 e 8,90\%, respectivamente. 0 emprego de A. brasilense melhora a qualidade fisiológica das sementes de milho pelo teste de frio sem solo.

Palavras-chave: Azospirillum brasilense, germinação, Herbaspirillum seropedicae, vigor, Zea mays L.

\section{Quality of corn seed in response to nitrogen fertilization and inoculation with diazotrophic bacteria}

\begin{abstract}
In the search for elevating high current levels of productivity and reduction in production costs of corn seeds in Brazil, new technologies are being incorporated into the production system. The aim of this study was to evaluate the physiological quality of seeds of maize in response to nitrogen fertilization and inoculation with Azospirillum brasiliense and Herbaspirillum seropedicae. Two experiments were installed, and in the first the design adopted was a randomized block, and in the second experiment, the design used was a completely randomized, both with nine treatments (control without $\mathrm{N}$ and without inoculation, control without $\mathrm{N}$ and with $A$. brasilense, control without $\mathrm{N}$ and with $H$. seropedicae, $30 \mathrm{~kg} \mathrm{~N} \mathrm{ha}^{-1}$ in sowing, $30 \mathrm{~kg} \mathrm{~N}^{-1}$ in sowing $+A$. brasilense, $30 \mathrm{~kg} \mathrm{~N} \mathrm{ha}^{-1}$ in sowing $+H$. seropedicae, $30 \mathrm{~kg} \mathrm{~N}^{-1} \mathrm{a}^{-1}$ in sowing $+90 \mathrm{~kg} \mathrm{~N} \mathrm{ha}^{-1}$ in topdressing, $30 \mathrm{~kg} \mathrm{~N}^{-1}{ }^{-1}$ in sowing $+A$. brasilense $+90 \mathrm{~kg} \mathrm{~N} \mathrm{ha}^{-1}$ in topdressing; $30 \mathrm{~kg} \mathrm{~N} \mathrm{ha}^{-1}$ in sowing $+\mathrm{H}$. seropedicae $+90 \mathrm{~kg} \mathrm{~N} \mathrm{ha}^{-1}$ in topdressing) and four replications. The variables evaluated were: percentage and first count of germination, dry mass and length of seedling, accelerated aging, cold test and electrical conductivity. The dry mass production are affected by inoculation with diazotrophic bacteria in association with nitrogen fertilization. Inoculation of corn seeds with $A$. brasilense, $H$. seropedicae and the use of nitrogen fertilizer promotes increase in productivity of corn seed to the extent of $4.73 ; 5.17$ to $8.90 \%$, respectively. The use of $A$. brasilense improves the physiological quality of seeds of maize by cold test without soil.
\end{abstract}

Key words: Azospirillum brasilense, germination, Herbaspirillum seropedicae, vigour, Zea mays L. 


\section{Introdução}

No agronegócio brasileiro a cultura do milho se tem destacado como uma das principais atividades, cuja área plantada no Brasil, na safra 2012/2013, foi de 156,5 mil hectares, com produção estimada de $72.569,9$ toneladas de grãos (CONAB, 2013).

Dentre os nutrientes minerais, o nitrogênio $(\mathrm{N})$ é um dos elementos mais importantes, sendo requerida sua aplicação em grandes quantidades para suprir a demanda da cultura (Dotto et al., 2010), visto que o único processo biológico de obtenção de $\mathrm{N}$ disponível na natureza, é a fixação biológica de nitrogênio atmosférico $(\mathrm{FBN})$ realizado por um grupo restrito de organismos ditos diazotróficos.

As bactérias diazotróficas, do gênero Azospirillum e Herbaspirillum, se destacam por sua capacidade de fixar nitrogênio atmosférico e por estimular o crescimento das plantas por meio da produção de fito-hormônios, de forma a permitir seu bom desenvolvimento (Huergo et al., 2008; Cassán et al., 2008), haja vista que, quando associadas à rizosfera, podem contribuir com a adubação nitrogenada (Cavallet et al., 2000).

$\mathrm{O}$ efeito do Azospirillum spp. e Herbaspirillum spp. no desenvolvimento do milho e de outras gramíneas tem sido pesquisado nos últimos anos (Bashan et al., 2006; Barassi et al., 2008; Cassán et al., 2009; Hungria et al., 2010; Braccini et al., 2012) não só quanto ao rendimento das culturas mas também com relação às causas fisiológicas que, possivelmente, aumentam este rendimento esperando que a aplicação desta forma alternativa de adubo reduza a necessidade de aplicação de $\mathrm{N}$ fertilizante para a cultura.

Recentemente, alguns estudos têm sido realizados no sentido de se avaliar os aspectos benéficos da associação de bactérias diazotróficas com a germinação de sementes. Lee et al. (2006) verificaram que a inoculação de bactérias diazotróficas (Enterobacter sp. e Burkholderia sp.) favoreceu a porcentagem e a velocidade de germinação de sementes de arroz. Karthikeyan et al. (2007) observaram que a inoculação da semente de Catharanthus roseus L. com Azospirillum e Azotobacter aumentou a porcentagem de germinação, tal como o vigor e o acúmulo de massa seca das plântulas. Araújo et al. (2010) constataram que a inoculação com as bactérias diazotróficas aumentou a velocidade de germinação de sementes de arroz e reduziu a contaminação por fungos. Barilli et al. (2011) verificaram aumento na porcentagem de emergência, massa seca de raízes e da parte aérea com a inoculação de Azospirillum brasilense, em avaliações realizadas aos 12 dias após a semeadura, enquanto Pinto Junior et al. (2012) observaram que a porcentagem de emergência, massa seca das raízes e parte aérea e o número de raízes por plântula, aumentaram com a inoculação de diferentes estirpes de Azospirillum brasilense.

As plântulas vigorosas podem competir mais eficientemente, sobretudo em condições de estresse por luz, nutrientes e água, influenciando o estabelecimento da população e a produção de grãos (Farooq et al., 2006). Desta forma, a aplicação de bactérias diazotróficas com o objetivo de favorecer a germinação e o estabelecimento das plantas de milho, pode ser uma tecnologia de baixo custo e fácil adoção.
Com base no exposto objetivou-se avaliar a qualidade fisiológica de sementes de milho em resposta à adubação nitrogenada e à inoculação com Azospirillum brasilense e Herbaspirillum seropedicae.

\section{Material e Métodos}

O primeiro experimento foi realizado na área experimental da Embrapa Agropecuária Oeste, situada no município de Dourados - MS, de março a agosto de 2012. As coordenadas geográficas são: latitude de $22^{\circ} 14^{\prime} \mathrm{S}$, longitude de $54^{\circ} 9^{\prime} \mathrm{W}$ e altitude de $452 \mathrm{~m}$, o clima da região é do tipo Cwa, segundo a classificação de Köppen e o solo classificado como Latossolo Vermelho distroférrico, de textura muito argilosa (Embrapa, 2006). Os dados médios de temperatura e a precipitação pluviométrica durante a condução do experimento obtidos na Estação Agrometeorológica da Embrapa Agropecuária Oeste, Dourados, MS, se encontram na Figura 1.

Os resultados da análise química do solo, estão na Tabela 1 , na profundidade de $0-20 \mathrm{~cm}$, antes da instalação do experimento constatando-se, na análise granulométrica, $21,5 \%$ de areia, $11,5 \%$ de silte e $67 \%$ de argila.

O delineamento experimental utilizado foi o de blocos casualizados, com nove tratamentos e quatro repetições
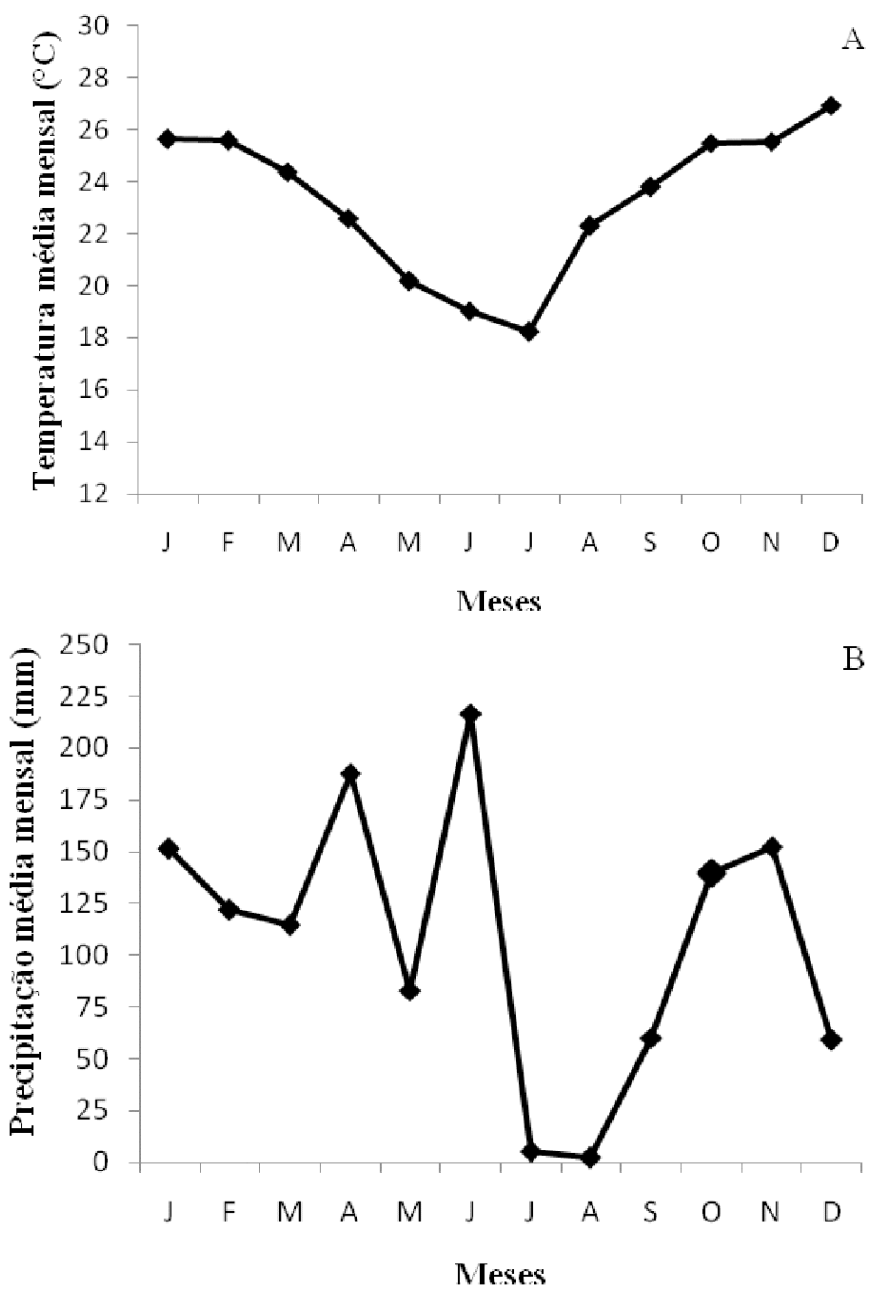

Figura 1. Temperatura $(A)$ e precipitação $(B)$ média mensal $(\mathrm{mm})$ no ano de 2012 
Tabela 1. Análise química do solo, antes da semeadura do milho

\begin{tabular}{ccccccccccccccccc}
\hline $\begin{array}{c}\text { Prof. } \\
(\mathbf{c m})\end{array}$ & $\begin{array}{c}\mathbf{p H} \\
(\mathbf{C a C l})\end{array}$ & $\mathbf{M O}$ & $\mathbf{C}$ & $\mathbf{P}$ & $\mathbf{K}$ & $\mathbf{C a}$ & $\mathbf{M g}$ & $\mathbf{A l}$ & $\mathbf{H}+\mathbf{A l}$ & $\mathbf{S B}$ & $\mathbf{C T C}$ & $\mathbf{V}$ & $\mathbf{Z n}$ & $\mathbf{C u}$ & $\mathbf{F e}$ & $\mathbf{M n}$ \\
\hline $0-20$ & 4,5 & 31,18 & 18,33 & 22,07 & 0,60 & 3,54 & 0,87 & 0,48 & 6,21 & 5,01 & 11,22 & 44,65 & 1,65 & 9,27 & 29,14 & 24,06 \\
\hline
\end{tabular}

(controle sem $\mathrm{N}$ e sem inoculação, controle sem $\mathrm{N}$ e com Azospirillum brasilense, controle sem $\mathrm{N}$ e com Herbaspirillum seropedicae, $30 \mathrm{~kg} \mathrm{~N}^{-1}$ na semeadura, $30 \mathrm{~kg} \mathrm{~N}^{-1}$ na semeadura $+A$. brasilense, $30 \mathrm{~kg} \mathrm{~N} \mathrm{ha}^{-1}$ na semeadura $+H$. seropedicae, $30 \mathrm{~kg} \mathrm{~N}$ ha $^{-1}$ na semeadura $+90 \mathrm{~kg} \mathrm{~N}^{-1}$ na cobertura, $30 \mathrm{~kg} \mathrm{~N}^{-1}$ na semeadura + A. brasilense $+90 \mathrm{~kg} \mathrm{~N}$ $\mathrm{ha}^{-1}$ na cobertura e $30 \mathrm{~kg} \mathrm{~N} \mathrm{ha}^{-1}$ na semeadura $+H$. seropedicae $+90 \mathrm{~kg} \mathrm{~N} \mathrm{ha}^{-1}$ na cobertura).

A adubação nitrogenada (ureia - 45\% de N) foi aplicada no sulco na dose de $30 \mathrm{~kg} \mathrm{~N} \mathrm{ha}^{-1}$ na semeadura e $90 \mathrm{~kg} \mathrm{~N} \mathrm{ha}^{-1}$ aplicados em cobertura em duas vezes de $45 \mathrm{~kg} \mathrm{~N} \mathrm{ha}^{-1}$ na área total da parcela. Na cobertura, a primeira aplicação de $\mathrm{N}$ foi realizada no estádio de desenvolvimento $\mathrm{V} 4$, correspondo a quatro folhas completamente expandidas e a segunda aplicação foi no estádio de desenvolvimento V7, correspondente a sete folhas completamente expandidas.

As parcelas foram compostas de quatro linhas de seis metros de comprimento espaçadas $0,90 \mathrm{~m}$ entre linhas, com eliminação das duas linhas laterais e $0,5 \mathrm{~m}$ de cada extremidade da parcela, avaliando-se os cinco metros de cada uma das duas linhas centrais. A correção do solo foi realizada um mês antes da semeadura, na dose de $1720 \mathrm{~kg} \mathrm{ha}^{-1} \mathrm{de}$ calcário dolomítico (PRNT 100\%), considerando-se os resultados da análise do solo. Na semeadura, a adubação de base foi realizada aplicando-se $340 \mathrm{~kg} \mathrm{ha}^{-1}$ da formulação 0-20-20 para o suprimento de $60 \mathrm{~kg} \mathrm{ha}^{-1}$ de $\mathrm{P}_{2} \mathrm{O}_{5}$ e $\mathrm{K}_{2} \mathrm{O}$, respectivamente. $\mathrm{Na}$ área constatou-se uma irrigação suplementar para manutenção hídrica, devido às condições climáticas da região no período de plantio e desenvolvimento da cultura e os demais tratos culturais foram realizados de acordo com as exigências da cultura. A semeadura foi realizada manualmente, com o auxílio de uma "matraca", colocando-se duas sementes por cova do híbrido simples $\mathrm{P} 3646 \mathrm{H}$, provenientes da empresa Pioneer. As sementes foram previamente inoculadas com o produto comercial Azototal, no qual foi usada uma combinação de duas estirpes de Azospirillum brasilense (Ab-V5 e Ab-V6) em inoculante, na formulação líquida e o inoculante contendo estirpes de Herbaspirillum seropedicae (Z-94) na formulação à base de turfa, cedidos pela Embrapa Agrobiologia, Seropédica - RJ. A dose aplicada foi de $150 \mathrm{~mL}$ para cada 50 $\mathrm{kg}^{-1}$ de sementes de milho para o inoculante na formulação líquida e de $250 \mathrm{~g}$ para cada $10 \mathrm{~kg}^{-1}$ de sementes de milho do inoculante na formulação à base de turfa. A colheita do milho foi realizada manualmente, coletando-se todas as espigas da parcela útil as quais foram debulhadas com o auxílio de uma máquina manual; a massa de 100 sementes e a produtividade fora determinada em balança analítica, cujos resultados foram corrigidos posteriormente, para $13 \%$ de umidade enquanto no segundo experimento avaliou-se a qualidade fisiológica das sementes colhidas no experimento I, no Laboratório de Análise de Sementes da Faculdade de Ciências Agrárias da Universidade Federal da Grande Dourados, em Dourados, MS, em delineamento experimental inteiramente casualizado, com nove tratamentos e quatro repetições, conforme descritos acima.

Os lotes de sementes foram submetidos aos seguintes testes: Geminação - realizado com quatro repetições de 50 sementes por lote, em rolo de papel germitest, umedecido com quantidade de água equivalente a 2,5 vezes sua massa seca. Os rolos contendo as sementes foram colocados em germinador regulado na temperatura de $25{ }^{\circ} \mathrm{C}$ constantes, segundo as Regras para Análise de Sementes - RAS (Brasil, 2009). Primeira contagem - realizada em conjunto com o teste de germinação computando-se o número de plântulas normais obtidas aos quatro dias após a semeadura, conforme Brasil (2009). Comprimento de plântulas - realizado juntamente com o teste de germinação procedendo-se à medição, aos sete dias após a instalação do teste; os comprimentos médios das plântulas normais foram obtidos dividindo-se a soma das medidas tomadas das subamostras pelo número de plântulas normais mensuradas e os resultados expressos em $\mathrm{mm}$ plântula $^{-1}$. Massa seca de plântulas - as plântulas medidas anteriormente, separadas por tratamento e repetição foram postas em sacos de papel do tipo Kraft e levadas à estufa, com circulação forçada de ar, mantida na temperatura de 65 ${ }^{\circ} \mathrm{C}$, por $72 \mathrm{~h}$; o peso da massa seca total das plântulas obtido em balança de precisão $(0,001 \mathrm{~g})$ foi dividido pelo número de plântulas normais do teste de germinação (Nakagawa, 1999) e os resultados expressos em g plântula ${ }^{-1}$. Envelhecimento acelerado - utilizou-se a metodologia recomendada pela AOSA (1983) e descrita em Marcos Filho (1999) em caixas gerbox $(11,0 \times 11,0 \times 3,5 \mathrm{~cm})$, utilizando-se quatro repetições de 50 sementes distribuídas em camada uniforme e única sobre bandeja de tela metálica fixada no interior de caixa plástica contendo $40 \mathrm{~mL}$ de água destilada. As caixas, tampadas e acondicionadas em estufa, foram mantidas a $42{ }^{\circ} \mathrm{C}$ durante $96 \mathrm{~h}$ e após este período quatro repetições de 25 e 50 sementes foram submetidas à determinação do teor de água e ao teste padrão de germinação, respectivamente. A interpretação do teste foi realizada aos quatro dias após a semeadura, com os resultados expressos em porcentagem de plântulas normais. Teste de frio realizado com quatro repetições de 50 sementes selecionadas ao acaso da produção por tratamento, as quais foram distribuídas sobre o papel germitest previamente umedecido, da mesma maneira que para o teste de germinação. Após a montagem os rolos foram colocados em sacos plásticos e vedados sendo e só mantidos em câmara fria a $10^{\circ} \mathrm{C}$, por sete dias, de acordo com Carvalho \& Nakagawa (2012), sendo em seguida, transferidos para um germinador ajustado na temperatura de $25^{\circ} \mathrm{C}$ durante sete dias, procedendo-se à avaliação do número de plântulas normais, conforme Brasil (2009). Condutividade elétrica realizada segundo metodologia proposta pela AOSA (1983) com quatro repetições de 50 sementes, e massa conhecida, colocadas para embeber em recipientes plásticos contendo 75 $\mathrm{mL}$ de água deionizada, pelo período de $24 \mathrm{~h}$, em temperatura de $25{ }^{\circ} \mathrm{C}$. Em seguida, as amostras foram agitadas para 
homogeneização dos exsudados liberados na água, efetuandose a leitura da condutividade elétrica da solução de embebição em condutivímetro modelo Digimed, previamente calibrado, com eletrodo de constante 1,0 , expressando-se os resultados em $\mu$ mhos $\mathrm{cm}^{-1} \mathrm{~g}^{-1}$ de sementes (Vieira, 1994).

Os resultados obtidos foram submetidos à análise de variância e as médias comparadas pelo teste de Tukey a 5\% de probabilidade, utilizando-se o programa estatístico SISVAR (Ferreira, 2000).

\section{Resultados e Discussão}

Pelos resultados das Tabelas 2 e 3 houve resposta significativa entre os tratamentos para o comprimento, massa seca total de plântulas, produtividade e teste de frio. As doses de nitrogênio e a inoculação das sementes com bactérias diazotróficas não influenciaram a massa de 100 sementes, porcentagem nem a primeira contagem de germinação (Tabela 2). Quanto ao envelhecimento acelerado e à condutividade elétrica, não foi constatado efeito da inoculação com as bactérias nem com a aplicação do nitrogênio (Tabela 3).

A massa de 100 sementes, porcentagem de germinação e a primeira contagem, não diferiram estatisticamente do tratamento controle (Tabela 2); quando se trata de microrganismos diazotróficos associativos, nem sempre são observadas diferenças entre aqueles tratamentos inoculados quando comparados com as aplicações de fertilizantes nitrogenados. Reis Júnior et al. (2000) relataram que, em muitos casos, a ausência de resposta à inoculação de bactérias diazotróficas em gramíneas tem sido atribuída ao uso de linhagens inadequadas. Contudo, há consenso de que o genótipo da planta seja fatorchave para obtenção dos benefícios oriundos da fixação biológica de nitrogênio.

O comprimento de plântulas foi afetado pela adubação nitrogenada e a inoculação com bactérias diazotróficas, diferindo estaticamente do tratamento controle, ou seja, os tratamentos inoculados com Azospirillum brasilense, Herbaspirillum seropedicae e aqueles em associação com a adubação nitrogenada apresentaram comprimento de plântulas superior ao tratamento controle (sem $\mathrm{N}$ e sem inoculação) (Tabela 2). Em milho, Conceição et al. (2008) observaram que a inoculação com bactérias diazotróficas, embora não tenha afetado a germinação das sementes aumentou o desenvolvimento da parte aérea das plantas devido, provavelmente, à ação das mesmas sobre o alongamento celular em virtude da turgescência vacuolar. Biswas et al. (2000) constataram aumento do coleóptilo e da emissão de raiz primária após a inoculação de plântulas de arroz com estirpes de Rhizobium e aumento na velocidade de emergência das plântulas, em condições de casa de vegetação. Karthikeyan et

Tabela 2. Valores de F, coeficiente de variação (CV), diferença mínima significativa (DMS) e teste de Tukey para massa de 100 sementes (M100S), porcentagem de germinação $(\mathrm{G})$, primeira contagem (PC), comprimento de plântula (CP) e massa seca total (MST) de plântulas de milho em resposta às doses de nitrogênio e à inoculação com bactérias diazotróficas, Dourados, MS (2012)

\begin{tabular}{|c|c|c|c|c|c|}
\hline \multirow{2}{*}{ Tratamentos } & \multirow{2}{*}{$\begin{array}{l}\text { M100S } \\
\text { (g) }\end{array}$} & $\mathbf{G}$ & PC & \multirow{2}{*}{$\begin{array}{c}\text { CP } \\
\left(\mathrm{cm} \text { plântula }{ }^{-1}\right)\end{array}$} & \multirow{2}{*}{$\begin{array}{c}\text { MST } \\
\text { (g plântula }^{-1} \text { ) }\end{array}$} \\
\hline & & \multicolumn{2}{|c|}{$\%$} & & \\
\hline Controle & $36,07 \mathrm{a}$ & $96 \mathrm{a}$ & $87 \mathrm{a}$ & $15,00 \mathrm{~b}$ & $1,23 \mathrm{c}$ \\
\hline Azosprillum brasilense & 35,79 a & 93 a & $88 \mathrm{a}$ & 21,68 a & $1,32 \mathrm{bc}$ \\
\hline Herbaspirillum seropedicae & 35,31 a & $96 a$ & $90 \mathrm{a}$ & $20,64 a$ & $1,59 a b$ \\
\hline $30 \mathrm{~kg} \mathrm{~N} \mathrm{ha}^{-1}$ na semeadura & 35,26 a & 94 a & $87 \mathrm{a}$ & $20,92 \mathrm{a}$ & $1,61 a b$ \\
\hline $30 \mathrm{~kg} \mathrm{~N} \mathrm{ha}^{-1}$ na semeadura $+A$. brasilense & 34,67 a & $96 \mathrm{a}$ & $89 a$ & $21,12 \mathrm{a}$ & $1,54 a b c$ \\
\hline $30 \mathrm{~kg} \mathrm{~N} \mathrm{ha}^{-1}$ na semeadura $+H$. seropedicae & 35,56 a & $95 \mathrm{a}$ & $86 \mathrm{a}$ & $22,65 \mathrm{a}$ & $1,60 \mathrm{ab}$ \\
\hline $30 \mathrm{~kg} \mathrm{~N} \mathrm{ha}^{-1}$ na semeadura $+90 \mathrm{~kg} \mathrm{~N} \mathrm{ha}^{-1}$ na cobertura & 36,21 a & $97 \mathrm{a}$ & 93 a & $21,56 a$ & $1,67 \mathrm{a}$ \\
\hline $30 \mathrm{~kg} \mathrm{~N} \mathrm{ha}^{-1}$ na semeadura $+A$. brasilense $+90 \mathrm{~kg} \mathrm{~N} \mathrm{ha}^{-1}$ na cobertura & 35,87 a & 96 a & $91 \mathrm{a}$ & 23,27 a & $1,68 \mathrm{a}$ \\
\hline $30 \mathrm{~kg} \mathrm{~N} \mathrm{ha}^{-1}$ na semeadura $+H$. seropedicae $+90 \mathrm{~kg} \mathrm{~N} \mathrm{ha}^{-1}$ na cobertura & 36,33 a & $95 \mathrm{a}$ & 89 a & $21,60 \mathrm{a}$ & $1,79 a$ \\
\hline Média & 35,67 & 95 & 89 & 20,94 & 1,56 \\
\hline Teste $\mathrm{F}$ & $0,58^{\text {ns }}$ & $1,62^{\text {ns }}$ & $0,75^{\text {ns }}$ & $15,74^{*}$ & $7,12^{*}$ \\
\hline DMS & 3,30 & 4,46 & 12,08 & 2,85 & 0,31 \\
\hline CV(\%) & 3,89 & 1,97 & 5,71 & 5,72 & 8,44 \\
\hline
\end{tabular}

${ }^{*} \mathrm{e}^{\text {ns - }}$ significativo e não significativo. Médias seguidas da mesma letra na linha não diferem estatisticamente entre si pelo teste de Tukey, a $5 \%$ de probabilidade.

Tabela 3. Valores de F, coeficiente de variação (CV), diferença mínima significativa (DMS) e teste de Tukey para envelhecimento acelerado (EA), teste de frio $(\mathrm{TF})$, condutividade elétrica (CE) e produtividade de sementes de milho em resposta às doses de nitrogênio e à inoculação com bactérias diazotróficas. Dourados, MS (2012)

\begin{tabular}{|c|c|c|c|c|}
\hline \multirow{2}{*}{ Tratamentos } & EA & TF & \multirow{2}{*}{$\begin{array}{c}\text { CE } \\
\left(\mu \mathrm{mhos} \mathrm{cm}^{-1} \mathrm{~g}^{-1}\right)\end{array}$} & \multirow{2}{*}{$\begin{array}{c}\text { Produtividade } \\
\left(\mathrm{kg} \mathrm{ha}^{-1}\right)\end{array}$} \\
\hline & \multicolumn{2}{|c|}{$\%$} & & \\
\hline Controle & $93 a$ & $88 \mathrm{ab}$ & $0,0067 \mathrm{a}$ & $9460,57 \mathrm{bc}$ \\
\hline Azosprillum brasilense & 94 a & 94 a & $0,0068 \mathrm{a}$ & $9430,83 \mathrm{bc}$ \\
\hline Herbaspirillum seropedicae & 94 a & $82 a b$ & 0,0071 a & 9219,24 c \\
\hline $30 \mathrm{~kg} \mathrm{~N} \mathrm{ha}^{-1}$ na semeadura & $93 a$ & $79 \mathrm{~b}$ & 0,0064 a & $9360,16 \mathrm{bc}$ \\
\hline $30 \mathrm{~kg} \mathrm{~N} \mathrm{ha}^{-1}$ na semeadura $+A$. brasilense & $97 \mathrm{a}$ & $92 a b$ & $0,0085 \mathrm{a}$ & $9561,27 \mathrm{bc}$ \\
\hline $30 \mathrm{~kg} \mathrm{~N} \mathrm{ha}^{-1}$ na semeadura $+H$. seropedicae & $91 \mathrm{a}$ & $87 \mathrm{ab}$ & 0,0079 a & $9403,88 \mathrm{bc}$ \\
\hline $30 \mathrm{~kg} \mathrm{~N} \mathrm{ha}^{-1}$ na semeadura $+90 \mathrm{~kg} \mathrm{~N}^{-1}$ na cobertura & $92 a$ & $85 a b$ & $0,0061 \mathrm{a}$ & 10303,44 a \\
\hline $30 \mathrm{~kg} \mathrm{~N} \mathrm{ha}^{-1}$ na semeadura $+A$. brasilense $+90 \mathrm{~kg} \mathrm{~N} \mathrm{ha}^{-1}$ na cobertura & $90 \mathrm{a}$ & $83 a b$ & $0,0079 \mathrm{a}$ & $9931,03 a b$ \\
\hline $30 \mathrm{~kg} \mathrm{~N} \mathrm{ha}^{-1}$ na semeadura $+H$. seropedicae $+90 \mathrm{~kg} \mathrm{~N} \mathrm{ha}^{-1}$ na cobertura & $90 \mathrm{a}$ & $82 \mathrm{ab}$ & 0,0076 a & $9976,98 \mathrm{ab}$ \\
\hline Média & 92 & 86 & 0,007 & 9627,49 \\
\hline Teste F & $0,93^{\text {ns }}$ & $2,76^{*}$ & $1,03^{\text {ns }}$ & $2,38^{*}$ \\
\hline DMS & 11,28 & 14,03 & 0,003 & 673,70 \\
\hline CV $(\%)$ & 5,13 & 6,90 & 21,13 & 4,82 \\
\hline
\end{tabular}

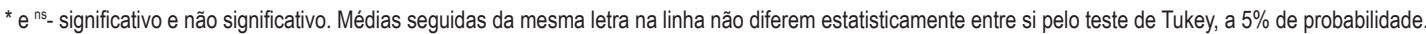


al. (2007) também observaram que a inoculação da semente de Catharanthus roseus (L.) com bactérias diazotróficas (Azospirillum e Azotobacter) aumentou o comprimento de raiz, a parte aérea e o vigor e o acúmulo de massa seca das plântulas.

A presença de bactérias fixadoras de nitrogênio e/ou do adubo nitrogenado favoreceu a produção de massa seca total, tal como a ausência do nitrogênio diminuiu a produção de massa seca (Tabela 2). O rendimento de massa seca variou de 1,23 $\mathrm{g} \mathrm{planta}^{-1}$ no tratamento controle, a 1,79 $\mathrm{g} \mathrm{planta}^{-1}$ no tratamento inoculado com Herbaspirillum seropedicae e acrescidos de $30 \mathrm{~kg} \mathrm{~N}^{-1}$ na semeadura $+90 \mathrm{~kg} \mathrm{~N} \mathrm{ha}^{-1}$ na cobertura. Destaca-se que o último tratamento foi superior $(\mathrm{p} \leq 0,05)$ ao controle e similar aos demais tratamentos (Tabela 2), nos quais proporcionou incremento na produção de massa seca, da ordem de $45,52 \%$ em relação ao controle (sem N e sem inoculação). Os dados obtidos confirmam a relação benéfica proporcionada pela inoculação de Herbaspirillum spp. nas plantas de milho uma vez que aquelas inoculadas com a bactéria obtiveram o maior peso em relação à massa seca total salientando que este maior incremento por plântulas inoculadas possa ser devido à produção de substâncias promotoras de crescimento pelas bactérias. Muñoz-Garcia et al. (1991) verificaram que a inoculação das sementes de milho com Azospirillum brasilense promoveu aumento na massa seca de raízes de 54 a $86 \%$ e de 23 a 64\% na massa seca da parte aérea. Reis Júnior et al. (2008) obtiveram incremento de $14 \%$ na massa seca de plantas de milho inoculadas com Azospirillum amazonense. Piccinin et al. (2011) e Braccini et al. (2012) constataram aumento relativo na produção de massa seca com a inoculação de sementes de milho com Azospirillum brasilense. Resultados similares também foram obtidos por Ferreira et al. (2010) e Sabino et al. (2012) em plantas de arroz inoculadas com Herbaspirillum seropedicae e Azospirillum brasilense, respectivamente.

$\mathrm{O}$ vigor, determinado pelo de envelhecimento acelerado e pela condutividade elétrica, não foi afetado pela adubação nitrogenada nem pela inoculação com bactérias diazotróficas, ou seja, não houve diferença significativa entre os tratamentos (Tabela 3). Bassan et al. (2001) também não verificaram efeito da inoculação de semente com Rhizobium tropici nos resultados do envelhecimento acelerado de sementes de feijão cultivar Pérola.

Quanto ao teste de frio sem solo, a diferença foi significativa entre os tratamentos, sendo que os tratamentos controle sem $\mathrm{N}$ e com Azospirillum brasilense e $30 \mathrm{~kg} \mathrm{~N} \mathrm{ha}^{-1}$ na semeadura diferiram estatisticamente entre si. O tratamento controle sem $\mathrm{N}$ e inoculado com Azospirillum brasilense apresentou o melhor desempenho, ou seja, maior porcentagem de plântulas normais (Tabela 3), podendo-se inferir que a inoculação de bactérias diazotróficas melhorou a qualidade fisiológica de sementes de milho. Resultados similares foram obtidos por Cassán et al. (2009) com as culturas do milho e da soja, nas quais o tratamento de sementes com cepas de Azospirillum brasilense promoveu aumentos significativos no vigor e na viabilidade das sementes. Por outro lado, com o tratamento $30 \mathrm{~kg} \mathrm{~N} \mathrm{ha}^{-1}$ na semeadura obteve-se desempenho inferior ao do tratamento controle sem $\mathrm{N}$ e inoculado com Azospirillum brasilense, sendo possível afirmar que, de modo geral, apenas o manejo da adubação nitrogenada não melhorou a qualidade fisiológica das sementes. Concordando com os resultados da presente pesquisa, Meira et al. (2005) constataram que o nitrogênio aplicado nos diferentes estádios de desenvolvimento da cultura não interferiu na qualidade fisiológica das sementes do feijoeiro. Bassan et al. (2001) relataram que a aplicação de nutrientes sobre a qualidade das sementes ainda é contraditório, de forma que há necessidade de mais estudos sobre o assunto. As maiores produtividades de sementes de milho foram obtidas no tratamento correspondente à adubação com $30 \mathrm{~kg}$ $\mathrm{N} \mathrm{ha}^{-1}$ na semeadura $+90 \mathrm{~kg} \mathrm{~N} \mathrm{ha}^{-1}$ na cobertura, não diferindo estatisticamente dos tratamentos inoculados com Azospirillum brasilense e Herbaspirillum seropedicae acrescido $30 \mathrm{~kg} \mathrm{~N}$ $\mathrm{ha}^{-1}$ na semeadura $+90 \mathrm{~kg} \mathrm{~N} \mathrm{ha}^{-1}$ na cobertura (Tabela 3).

Destaca-se que o tratamento $30 \mathrm{~kg} \mathrm{~N} \mathrm{ha}^{-1}$ na semeadura + $90 \mathrm{~kg} \mathrm{~N} \mathrm{ha}{ }^{-1}$ na cobertura promoveu aumento na produtividade de sementes, da ordem de $8,9 \%$ em comparação com o tratamento controle, que não recebeu inoculação nem adubação nitrogenada; entretanto, os tratamentos com inoculação de Azospirillum brasilense e Herbaspirillum seropedicae acrescidos de $30 \mathrm{~kg} \mathrm{~N}$ ha $^{-1}$ na semeadura $+90 \mathrm{~kg} \mathrm{~N}^{-1}$ na cobertura, promoveram incrementos da ordem de 4,73 e $5,17 \%$, respectivamente.

Resultados similares em relação ao aumento de produtividade com o uso de Azospirillum também foram relatados por Didonet et al. (1996), em especial na presença de adubação nitrogenada indicando maior eficiência do nitrogênio mineral aplicado ao solo quando da associação Azospirilum-milho. Cavallet et al. (2000) verificaram que a inoculação do produto comercial "Graminante", à base de Azospirillum spp. promoveu acréscimo de $17 \%$ na produtividade de grãos de milho. Hungria et al. (2010) e Lana et al. (2012) constataram que a inoculação com Azospirillum brasilense aumentou a produtividade de grãos de milho, de 26 e 15,4\%, respectivamente, enquanto Kappes et al. (2013) obtiveram acréscimos de 9,4\% na produtividade de grãos de milho quando as sementes foram inoculadas com Azospirillum brasilense. Alves (2007) observou percentuais de incrementos para produtividade do milho de 24 e $34 \%$ com a utilização de Herbaspirillum seropedicae na safrinha e na safra e que a inoculação pode suprir até $40 \mathrm{~kg} \mathrm{~N} \mathrm{ha}^{-1}$.

Segundo Huergo et al. (2008) e Hungria et al. (2011) aumentos na produção de massa seca e na produtividade de sementes de milho em resposta à inoculação podem ser atribuídos ao estímulo que as bactérias diazotróficas fornecem ao desenvolvimento de sistema radicular com aumento na densidade de pêlos radiculares, comprimento, volume e número de raízes lateriais, resultando em maior capacidade de absorção e utilização de água e nutrientes.

\section{Conclusões}

O comprimento de plântulas e a produção de massa seca são afetados pela inoculação com as bactérias diazotróficas em associação com a adubação nitrogenada.

A inoculação das sementes de milho com Azospirillum brasilense, Herbaspirillum seropedicae e o uso da adubação nitrogenada promovem aumentos na produtividade de sementes 
de milho, da ordem de 4,73, 5,17 e 8,90\%, respectivamente. O uso de Azospirillum brasilense melhora a qualidade fisiológica das sementes de milho pelo teste de frio sem solo.

\section{Literatura Citada}

Alves, G. C. Efeito da inoculação de bactérias dos gêneros Herbaspirillum e Burkholderia na cultura do milho. Rio de Janeiro: UFRRJ, 2007. 53p. Dissertação Mestrado. <http:// www.ia.ufrrj.br/cpacs/arquivos/teses_dissert/13_Gabriela Cavalcanti_Alves.pdf>. 04 Mar. 2013.

Araújo, A. E. S.; Rosseto, C. A. V.; Baldani, V. L. D.; Baldani, J. I. Germinação e vigor de sementes de arroz inoculadas com bactérias diazotróficas. Ciência e Agrotecnologia, v.34, n.4, p.932-939, 2010. <http://dx.doi.org/10.1590/ S1413-70542010000400019>.

Association of Official Seed Analysts - AOSA. Seed vigour testing handbook. Lincoln: Aosa, 1983. 88p. (Handbook on seed testing. Contribuition, 32).

Barassi, C. A.; Sueldo, R. J.; Creus, C. M.; Carrozzi, L. E.; Casanova, W. M.; Pereyra, M. A. Potencialidad de Azospirillum en optimizer el crecimiento vegetal bajo condiciones adversas. In: Cassán, F.D.; Garcia de Solamone, I. (Eds.). Azospirillum sp.: cell physiology, plant interactions and agronomic research in Argentina. Buenos Aires: Asociación Argentina de Microbiologia, 2008. p.4959.

Barilli, D. R.; Tsutsumi, C. Y.; May, A.; Miranda, A. M.; Hachmann, T. L.; Modonlon, T. A. Eficiência na inoculação do milho com Azospirillum brasilense em diferentes períodos antes da semeadura. Cadernos de Agroecologia, v.6, n.2, p.1-5, 2011. <http://www.aba-agroecologia.org.br/ revistas/index.php/cad/article/viewFile/11724/8090>. 03. Set. 2012.

Bashan, Y.; Bustillos, J. J.; Leyva, L. A.; Hernandez, J. P.; Bacilio, M. Increase in auxiliary photo protective photosynthetic pigments in wheat seedlings induced by Azospirillum brasilense. Biology and Fertility of Soils, v.42, n.4, p.279-285, 2006. <http://dx.doi.org/10.1007/ s00374-005-0025-x>.

Bassan, D. A. Z.; Arf, O.; Buzetti, S.; Carvalho, M. A. C.; Santos, N. C. B. S; Sá, M. E. Inoculação de sementes e aplicação de nitrogênio e molibdênio na cultura do feijão de inverno: produção e qualidade fisiológica de sementes. Revista Brasileira de Sementes, v.23, n.1, p.76-83, 2001. $<$ http://www.abrates.org.br/revista/artigos/2001/v23n1/ artigo11.pdf $>04$ Set. 2012.

Biswas, J. C.; Ladha, J. K.; Dazzo, F. B.; Yanni, Y. G.; Rolfe, B. G. Rhizobial inoculation influences seedling vigor and yield of rice. Agronomy Journal, v.92, n.5, p.880-886, 2000. <http://dx.doi.org/10.2134/agronj2000.925880x>.

Braccini, A. L.; Dan, L. G. M; Piccinin, G. G.; Albrecht, L. P.; Barbosa, M. C. Seed inoculation with Azospirillum brasilense, Associated with the use of bioregulators in maize. Revista Caatinga, v.25, n.2, p.58-64, 2012. $<$ http://200.137.6.4/revistas/index.php/sistema/article/ view/2241>. 04 Set. 2012.
Brasil. Ministério da Agricultura, Pecuária e Abastecimento. Regras para análise de sementes. Secretaria de Defesa Agropecuária. Brasília: MAPA/ACS, 2009. 395p. <http:// www.bs.cca.ufsc.br/publicacoes/regras $\% 20$ analise $\% 20$ sementes.pdf>. 07 Set. 2012.

Carvalho, N. M.; Nakagawa, J. Sementes: ciências, tecnologia e produção. 5.ed. Jaboticabal: FUNEP, 2012. 590p.

Cassán, F.; Perrig, D.; Sgroy, V.; Masciarelli, O.; Penna, C.; Luna, V. Azospirillum brasilense Az39 and Bradyrhizobium japonicum E109, inoculated singly or in combination, promote seed germination and early seedling growth in corn (Zea mays L.) and soybean (Glycine max L.). European Journal of Soil Biology, v.45, n.1, p.28-35, 2009. $<$ http://dx.doi.org/10.1016/j.ejsobi.2011.05.003>.

Cassán, F.; Sgroy, V.; Perrig, D.; Masciarelli, O.; Luna, V. Producción de fitohormonas por Azospirillum sp. Aspectos fisiológicos y tecnológicos de la promoción del crecimiento vegetal. In: Cassán, F. D.; Garcia de Salamone, I. (Ed.) Azospirillum sp.: cell physiology, plant interactions and agronomic research in Argentina. Buenos Aires: Asociación Argentina de Microbiologia, 2008. p.61-86. <http://www. bashanfoundation.org/cassan/cassancapitulo4.pdf $>$. 03 Set. 2012.

Cavallet, L. E.; Pessoa, A. C. S.; Helmich, J. J.; Helmich, P. R.; Ost, C. F. Produtividade do milho em resposta à aplicação de nitrogênio e inoculação das sementes com Azospirillum spp. Revista Brasileira de Engenharia Agrícola e Ambiental, v.4, n.1, p.129-132, 2000. <http://dx.doi.org/10.1590/ S1415-43662000000100024>.

Companhia Nacional de Abastecimento - CONAB. 2013. Acompanhamento da safra brasileira 2012/2013: quinto levantamento, Fevereiro, 2013. Companhia Nacional de Abastecimento, CONAB, 2013. <http://www.conab.gov. br/OlalaCMS/uploads/arquivos/12_03_13_11_04_08 boletim_marco_2013.pdf>. 05 Mar. 2013.

Conceição, P. M.; Vieira, H. D.; Canellas, L. P.; Marques Junior, R. B.; Olivares, F. L. Recobrimento de sementes de milho com ácidos húmicos e bactérias diazotróficas endofíticas. Pesquisa Agropecuária Brasileira, v.43, n.4, p.545-548, 2008. <http://dx.doi.org/10.1590/S0100204X2008000400015>. 07 Set. 2012.

Didonet, A. D.; Rodrigues, O; Kenner, M. H. Acúmulo de nitrogênio e de massa seca em plantas de trigo inoculadas com Azospirillum brasilense. Pesquisa Agropecuária Brasileira, v.16, n.9, p.645-651, 1996. <http://seer.sct. embrapa.br/index.php/pab/article/viewFile/4533/1819>. 15 Set. 2012.

Dotto, A. P.; Lana, M. C.; Steiner, F.; Frandoloso, J. F. Produtividade do milho em resposta à inoculação com Herbaspirillum seropedicae sob diferentes níveis de nitrogênio. Revista Brasileira de Ciências Agrárias, v.5, n.3, p.376-382, 2010. <http://dx.doi.org/10.5039/agraria. v5i3a898>.

Empresa Brasileira de Pesquisa Brasileira - Embrapa. Centro Nacional de Pesquisa de Solos. Sistema brasileiro de classificação de solos. Brasília: Embrapa/DPI, 2006. 306p. 
Farooq, M.; Barsa, S. M. A.; Wahid, A. Priming of field-sown rice seed enhances germination, seedling establishment, allometry and yield. Plant Growth Regulator, v.49, n.2-3, p.285-294, 2006. <http://dx.doi.org/10.1007/s10725-0069138-y>.

Ferreira, D.F. Sistema de análises de variância para dados balanceados (SISVAR). Lavras: UFLA, 2000.

Ferreira, J. S.; Baldani, J. I.; Baldani, V. L. D. Seleção de inoculantes à base de turfa contendo bactérias diazotróficas em duas variedades de arroz. Acta Scientiarum Agronomy, v.32, n.1, p.179-185, 2010. <http://dx.doi.org/10.4025/ actasciagron.v32i1.732>.

Huergo, L. F.; Monteiro, R. A.; Bonatto, A. C.; Rigo, L. U.; Steffens, M. B. R.; Cruz, L. M.; Chubatsu, L. S.; Souza, E. M.; Pedrosa, F. O. Regulation of nitrogen fixation in Azospirillum brasilense In: Cassán, F. D.; Garcia de Salamone, I. (Ed.) Azospirillum sp.: cell physiology, plant interactions and agronomic research in Argentina. Buenos Aires: Asociación Argentina de Microbiologia, 2008.p.1735.

Hungria, M. Inoculação com Azospirillum brasiliense: inovação em rendimento a baixo custo. Londrina: Embrapa Soja, 2011.36p. <http://www.cnpso.embrapa.br/download/ doc325.pdf>. 09 Out. 2013.

Hungria, M.; Campo, R. J.; Souza, E. M.; Pedrosa, F. O. Inoculation with selected strains of Azospirillum brasilense and A.lipoferum improves yields of maize and wheat in Brazil. Plant and Soil, v.331, n.1-2, p.413-425, 2010. $<$ http://dx.doi.org/10.1007/s11104-009-0262-0>.

Kappes, C.; Arf, O.; Arf, M. V.; Ferreira, J. P.; Dal Bem, E. A.; Portugal, J. R.; Vilela, R. G. Inoculação de sementes com bactéria diazotrófica e aplicação de nitrogênio em cobertura e foliar em milho. Semina: Ciências Agrárias, v.34, n.2, p.527-538, 2013. <http://dx.doi.org/10.5433/16790359.2013v34n2p527>.

Karthikeyan, B.; Jaleel, C. A.; Gopi, R.; Deiveekasundaran, M. Alterations in seedling vigour and antioxidant enzyme activities in Catharanthus roseus under seed priming with native diazotrophs. Journal of Zhejiang University, v.8, n.7, p.453-457, 2007. <http://dx.doi.org/10.1631/jzus.2007. B0453>.

Lana, M. C.; Dartora, J.; Marini, M.; Hann, J. E. Inoculation with Azospirillum, associated with nitrogen fertilization in maize. Revista Ceres, v.59, n.3, p.399-405, 2012. <http:// dx.doi.org/10.1590/S0034-737X2012000300016>.

Lee, H. S.; Madhaiyan, M.; Kim, C. W.; Choi, S. J.; Chung, K. Y. Physiological enhancement of early growth of rice seedlings (Oryza sativa L.) by production of phytohormone of $\mathrm{N}_{2}$ fixing methylotrophic isolates. Biology and fertility of soils, v.42, n.5, p.402-408, 2006. <http://dx.doi. org/10.1007/s00374-006-0083-8>.
Marcos Filho, J. Teste de envelhecimento acelerado. In: Krzyzanowski, C. F.; Vieira, R. D.; França-Neto, J. B. (Eds.). Vigor de sementes: conceitos e testes. Londrina: ABRATES, 1999. p.1-24.

Meira, F. A.; Sá, M. E., Buzetti, S.; Arf, O. Doses e épocas de aplicação de nitrogênio no feijoeiro irrigado cultivado em plantio direto. Pesquisa Agropecuária Brasileira, v.40, n.4, p.383-388, 2005. <http://dx.doi.org/10.1590/S0100204X2005000400010>.

Muñoz-Garcia, A.; Caballero-Mellado, J.; Valdés, M. Promoción del crescimiento del maiz por cepas productoras de siderófos de Azospirillum y Pseudomonas fluorescentes. In: Congresso Nacional de La Fijacion biologica del Nitrogeno, 3., y Encuentro Iberoamericano de Investigacion sobre Fijacion de Nitrogeno, 1., 1991, Cuernavaca. Anais... Cuernavaca: CONFINIT, 1991. p.61.

Nakagawa, J. Testes de vigor baseado no desempenho das plântulas. In: Krzyzanowski, F. C.; Vieira, R. D.; França Neto, J. B. (Eds.). Vigor de sementes: conceitos e testes. Londrina: ABRATES, 1999. p.1-24.

Piccinin, G. G.; Dan, L. G. M.; Braccini, A. L.; Mariano, D. C.; Okumura, R. S.; Bazo, G. L.; Ricci, T. T. Agronomic efficiency of Azospirillum brasilense in physiological parameters and yield components in wheat crop. Journal of Agronomy, v.10, n.4, p.132-135, 2011. <http://dx.doi. org/10.3923/ja.2011.132.135>.

Pinto Junior, A. S.; Guimarães, V. F.; Rodrigues, L. F. O. S.; Silva, M. B.; Inagaki, A. M.; Diamante, M. S.; Offemann, L. C. Qualidade de sementes de milho oriundas da inoculação combinada de três estirpes de Azospirillum brasilense. In: Congresso Nacional de Milho e Sorgo, 29., 2012, Águas de Lindóia. Anais... Águas de Lindóia: ABMS, 2012. <http:// www.abms.org.br/29cn_milho/02658.pdf>. 15 Set. 2012.

Reis Júnior, F. B.; Machado, C. T. T.; Machado, A. T.; Sodek, L. Inoculação de Azospirillum amazonense em dois genótipos de milho sob diferentes regimes de nitrogênio. Revista Brasileira de Ciência do Solo, v.32, n.3, p.1139-1146, 2008. $<$ http://dx.doi.org/10.1590/S0100-06832008000300022>.

Reis Júnior, F. B.; Silva, L. G.; Reis, V. M.; Döbereiner, J. Ocorrência de bactérias diazotróficas em diferentes genótipos de cana-de-açúcar. Pesquisa Agropecuária Brasileira, v.35, n.5, p.985-994, 2000. <http://dx.doi. org/10.1590/S0100-204X2000000500016>.

Sabino, D. C. C.; Ferreira, J. S.; Guimarães, S. L.; Baldani, V. L. D. Bactérias diazotróficas como promotoras do desenvolvimento inicial de plântulas de arroz. Enciclopédia Biosfera, v.8, n.15, p.2337-2345, 2012. <http://www. conhecer.org.br/enciclop/2012b/ciencias\%20biologicas/ bacterias.pdf $>$. 12 Nov. 2013.

Vieira, R. D. Teste de condutividade elétrica. In: Vieira, R. D.; Carvalho, N. M. (Eds.). Testes de vigor em sementes. Jaboticabal: FUNEP, 1994. p.103-139. 